\title{
O financiamento das empressas brasileiras à luz das teorias pecking order e market timing: evidências da regionalidade
}

\author{
Thayla Machado Guimarães Iglesias (iD), Thayse Machado Guimarães ${ }^{(D)}$, Vinícius Silva Pereira ${ }^{(i)}$, Antônio Sérgio \\ Torres Penedo iD
}

Universidade Federal de Uberlândia Uberlândia-MG, Brasil.

\section{$\bigotimes$}

'thayla.adm@gmail.com

2thaysemg.adm@gmail.com

3viniciuss56@gmail.com

4drpenedo@gmail.com

Editado por:

Orleans Silva Martins

Paulo Roberto da Cunha

\section{Resumo}

Objetivo: Este estudo tem como objetivo compreender como os fatores macroeconômicos e as características das firmas impactam na definição da estrutura de capital das empresas brasileiras, tendo em vista o contexto regional.

Método: $O$ estudo envolveu 426 empresas brasileiras, não financeiras, listadas na B3 durante o período de 2007 a 2017. Na perspectiva interna, foram utilizadas as variáveis liquidez, $R O E$, tangibilidade e tamanho, enquanto, na abordagem externa, as variáveis PIB, inflação e a identificação dos períodos de crise, representados pelos anos 2008 e 2015.

Resultados: Os resultados evidenciaram que a maioria das organizações está situada nas regiões sudeste e sul (86\%), sendo o controle pelas regiões um fator importante na tomada de decisão a respeito do financiamento das empresas. Além disso, foi corroborada a teoria Pecking Order, no que tange às características das firmas, uma vez que as empresas tendem a priorizar a utilização de recursos internos ao de terceiros, especialmente em momentos de recessão econômica, quando há maior impacto nos lucros empresariais. No entanto, não foi ratificada a teoria Market Timing, o que sugere que as empresas não tendem a observar as janelas de oportunidade para a emissão dos títulos.

Contribuições: É relevante investigar como as decisões de financiamento das empresas são impactadas por questões que vão além das características das firmas, isto é, como elas sofrem a influência do ambiente no qual estão inseridas, sobretudo no que tange aos fatores macroeconômicos e ao contexto regional. Desse modo, entende-se que esta pesquisa avança na literatura não só por abranger os fatores externos, mas também por considerar as diferenças regionais do Brasil.

Palavras-chave: Endividamento. Regiões Brasileiras. Fatores Macroeconômicos. Características das Firmas.

Como citar:

Iglesias, T. M. G., Guimarães, T. M., Pereira, V. S., \& Penedo, A. S. T. (2021). O FINANCIAMENTO DAS EMPRESAS BRASILEIRAS À LUZ DAS TEORIAS PECKING ORDER E MARKET TIMING: EVIDÊNCIAS DA REGIONALIDADE. Advances in Scientific and Applied Accounting, 14(2), 080-094/095. https://doi.org/10.14392/asaa.2021140204 


\section{Introdução}

A literatura sobre estrutura de capital evidencia que as decisões de financiamento das empresas ainda incitam investigação acadêmica e maior compreensão dos agentes do mercado. Estudos anteriores demonstram a insuficiência de apenas uma teoria para explicar as decisões de financiamento das empresas (Allini, Rakha, McMillan \& Caldarelli, 2017; Cardoso \& Pinheiro, 2020), visto que não há evidências sólidas, com análises empíricas, que apontem com clareza as forças e fraquezas das principais teorias (Frank \& Goyal, 2009).

Entende-se que as decisões de financiamento são influenciadas tanto por fatores internos quanto pelo ambiente no qual as empresas estão inseridas (Santos, 2013; Ahuja \& Kalra, 2020). No entanto, são poucos os estudos que intentam compreender a relação das decisões de financiamento com as características macroeconômicas (Bastos, Nakamura \& Basso, 2009; Bernardo, Albanez \& Securato, 2018) e com o contexto regional (La Rocca, La Rocca \& Cariola, 2010; Palacín-Sánchez, Ramírez-Herrera \& Di Pietro, 2013; Palacín-Sánchez \& Di Pietro, 2016; Matias \& Serrasqueiro, 2017; Di Pietro, Palacín-Sánchez \& Roldán, 2018), sobretudo com o enfoque em grandes empresas.

Os impactos das variáveis macroeconômicas no financiamento corporativo podem ser distintos, visto que a estrutura de capital das organizações pode variar conforme oscilações, por exemplo, nas taxas de juros, câmbio e Produto Interno Bruto (PIB). Nesse sentido, conforme o contexto do país e das definições da política macroeconômica, estas variáveis podem ou não ser cruciais na proporção de capital de terceiros mantida pelas organizações (Cardoso \& Pinheiro, 2020).

Especialmente em momentos de recessão econômica, as empresas sofrem com limitação da demanda, elevação dos preços e, consequente, queda do produto interno bruto (PIB). Nestes cenários, há maiores desafios para a continuidade dos negócios e garantia da lucratividade das empresas. Sendo assim, em momentos de ruptura econômica, há alterações na disponibilidade de capital e são distintos os custos de dívida, que podem favorecer ou limitar a concessão do crédito (Brighetti \& Albanez, 2019; Cardoso \& Pinheiro, 2020).

O ambiente competitivo, no qual os negócios estão inseridos, faz com que os gestores se preocupem, cada vez mais, com a forma como financiam seus negócios e definem suas estruturas de capital (Jahanzeb, 2013), sobretudo em economias emergentes, cujos mercados são menos eficientes e há problemas mais críticos de assimetria da informação e seleção adversa (Allini et al., 2017), e em contextos de recessão econômica (Brighetti \& Albanez, 2019). Por isto, é relevante aprofundar na investigação deste tema, considerando-se o ambiente externo, com o enfoque regional.

A respeito do financiamento das organizações, conforme apresenta Myers (1984) na abordagem da teoria Pecking Order (POT), as empresas seguem uma sequência lógica e prioritária para o levantamento de recursos, também conhecida, no Brasil, como Teoria de Hierarquização de Fontes de Financiamento (THFF). De acordo com a Pecking Order, as organizações priorizam o financiamento interno, obtido por meio do fluxo de caixa gerado por adaptações no pagamento de dividendos e pelos lucros obtidos. Isso implica dizer que as empresas ajustam o pagamento de dividendos conforme as oportunidades de investimento. Vale destacar que, se o capital gerado internamente for inferior aos investimentos, é preciso recorrer ao financiamento externo por meio de emissão de títulos ao mercado de capitais.

Desse modo, dada a necessidade de financiamento externo, as companhias optam, primeiramente, por títulos de dívida, depois por títulos híbridos, como debêntures conversíveis e, posteriormente, pela emissão de ações (Myers, 1984).

Em uma perspectiva diferente, tem-se uma abordagem mais recente, nomeada Market Timing (MTT), a qual põe em evidência a relação da estrutura de capital com a performance das ações das empresas. Nesta perspectiva, as empresas têm a prática de emitir ações, quando estes ativos estão com preços mais elevados, e de comprá-las em momentos de baixa. Esta prática, portanto, tende a permitir que as organizações se beneficiem com as flutuações temporárias dos custos de emissão em relação ao custo de outras fontes de capital. A estrutura de capital das empresas seria, portanto, o resultado cumulativo das tentativas de sincronizar o mercado de ações (Baker \& Wurgler, 2002).

Conforme apresentam a literatura nacional e internacional, a estrutura de capital é influenciada por fatores (internos e externos) e, de acordo com as distintas teorias que surgem para melhor compreensão e investigação, são esperadas diferentes relações destas variáveis com a alavancagem das empresas. A maioria dos trabalhos tem buscado compreender como fatores das firmas impactam no financiamento corporativo, sendo, pois, mais recente a 
investigação que contempla variáveis macroeconômicas. Os estudos em linha com a teoria Pecking Order são: Bastos et al. (2009), Frank e Goyal (2009), Kayo e Kimura (2011), Santos (2013), Allini et al. (2017), Bernardo et al. (2018) e Brighetti e Albanez (2019). Ressalta-se que alguns destes trazem o comparativo das teorias, portanto, também visualizam-se investigações sob a ótica da teoria Market Timing: Santos (2013); Bernardo et al. (2018); e Kayo e Kimura (2011).

Abordagens empíricas sobre regionalidade ainda são incipientes na literatura, sobretudo com o enfoque nacional. Em se tratando de pesquisas internacionais e de economias emergentes, destacam-se algumas evidências sobre a China, conforme apresentam os estudos de Hasan, Kobeissi, Wang e Zhou (2017), Lv, Bian, Lee e He (2021) e Cong, Lo e Yu (2021).

Para Di Pietro et al. (2018), a existência de diferenças regionais no ambiente institucional de um país impacta na estrutura financeira das empresas, especialmente no contexto de pequenas e médias empresas. Nesse aspecto, tem-se os estudos de La Rocca et al. (2010), Palacín-Sánchez et al. (2013), Palacín-Sánchez e Di Pietro (2016), Matias e Serrasqueiro (2017) e Di Pietro et al. (2018). Entretanto, cabem investigações a despeito da regionalidade e o impacto na estrutura de capital das empresas, considerando-se empresas de maior porte.

Frente ao exposto, este estudo apresenta o seguinte problema de pesquisa: Qual é a influência dos fatores macroeconômicos e das características das firmas na definição da estrutura de capital das empresas brasileiras, considerando-se a abordagem regional? $O$ objetivo geral consiste, portanto, na compreensão de como os fatores macroeconômicos e as características das firmas impactam na definição da estrutura de capital das empresas brasileiras, tendo em vista o contexto regional. De maneira específica, almeja-se: (i) investigar as decisões de financiamento frente às alterações do PIB regional e da inflação a nível país, com ênfase na abordagem da Pecking Order e (ii) compreender a relação entre as decisões de financiamento e a abordagem do Market Timing. A amostra do estudo abrangeu 426 empresas brasileiras não financeiras, listadas na B3, com valor de mercado superior a $R \$ 10$ milhões no ano de 2017, no período de 2007 a 2017.

Esta pesquisa apresenta contribuições teóricas, pois, quando comparada com outras abordagens sobre o tema estrutura de capital, a investigação da relação com as variáveis macroeconômicas e institucionais é relativamente recente (Bernardo et al., 2018), especialmente no contexto regional (La Rocca et al., 2010; Palacín-Sánchez et al., 2013; Palacín-Sánchez \& Di Pietro, 2016; Matias \& Serrasqueiro, 2017; Di Pietro et al., 2018). Ademais, trabalhos com enfoque em economias emergentes e que trazem uma análise sob a ótica da Pecking Order e, também, do Market Timing não são muito comuns (Allini et al., 2017; Ahuja \& Kalra, 2020). Portanto, este estudo traz contribuições por demonstrar a realidade de um país emergente, em comparação com outras economias em desenvolvimento, bem como com países desenvolvidos. Outrossim, diferente de evidências anteriores, este trabalho centra-se na investigação da influência do contexto regional nas decisões de financiamento de grandes empresas brasileiras, às quais, geralmente, estão associadas investigações sobre variáveis ambientais ao nível multi country.

Este estudo também apresenta contribuições para os agentes econômicos, a saber: (i) para os reguladores, possibilita melhor compreensão da estrutura e desenvolvimento do mercado de capitais; (ii) para os gestores, garante melhor reconhecimento das necessidade de financiamento empresarial e as possibilidades de redução dos custos da dívida; e (iii) para os investidores, maior esclarecimento de como as empresas operam, gerando maior transparência das informações necessárias para as decisões de investimento (Allini et al., 2017). Dessa forma, é possível compreender como características internas e externas interferem no processo de tomada de decisão de financiamento, o que possibilita melhorar a atividade econômica, reduzir os custos de captação de recursos e, consequentemente, melhorar a competitividade das organizações (Santos, 2013).

\section{Referencial Teórico}

Nesta seção, discute-se a abordagem regional, bem como a estrutura de capital sob a ótica de duas teorias, ou seja, teoria Pecking Order (POT) e a teoria Market Timing (MTT), as quais fundamentam as hipóteses do estudo.

\subsection{Aspectos Gerais sobre a Regionalidade}

Para Pettinati (2012), a nova era iniciada pela globalização foi caracterizada por mudanças significativas na esfera tecnológica, relações de importação e exportação, padronização de produtos e hábitos, mas, em contrapartida, houve a imposição da cultura ocidental massificante. Somada a essa abordagem, Gil, Oliva, Novais e Silva (2013) destacam que essa nova visão de mundo trouxe consigo a promessa de maior liberdade para intercâmbio 
de bens e conhecimentos. Entretanto, como efeitos negativos, teve-se a informação concentrada nos detentores de poder e um sistema financeiro que serve aos anseios desses. Em decorrência disso, despertou-se o interesse pelo olhar regional e as relações que dele desdobram-se (Pettinati, 2012), ou seja, a valorização do regional apresentou-se como um contraponto ao aspecto global dominante (Gil et al., 2013).

Gil et al. (2013), por sua vez, compreendem que a região é fruto de uma construção social, que abrange construções intelectuais, cujo objeto é difícil experimentação e quantificação. Já Haesbaert (2010) retrata a região como produto e produtora das dinâmicas concomitantes entre a globalização e a fragmentação, construída por meio de atuação de diferentes sujeitos sociais, além de produto e produtora dos processos de diferenciações espaciais.

\subsection{Estudos empíricos sobre Regionalidade}

Hasan et al. (2017) investigaram os efeitos do financiamento bancário nas atividades empresariais regionais na China, no tocante a quantidade e a qualidade do financiamento bancário. Com base nos resultados, percebeu-se que a qualidade dos serviços bancários impacta sobremaneira no empreendedorismo dos mercados locais, especialmente nas regiões com altos níveis de atividades inovadoras. Ademais, a eficiência dos sistemas bancários locais é mais importante para a formação de pequenos negócios nas regiões com instituições subdesenvolvidas.

Lv et al. (2021), por sua vez, analisaram o índice de desenvolvimento nacional de finanças verdes na perspectiva de quatro regiões da China. Os resultados evidenciaram que, no geral, o plano de desenvolvimento de finanças verdes na China está em crescimento, mas não é alto, a lacuna interregional é a principal fonte de lacuna no desenvolvimento de finanças verdes no país e, ainda, o desenvolvimento de finanças verdes apresenta uma tendência de polarização, caracterizada por uma distribuição em escalada, partindo do leste, centro, oeste e, por fim, nordeste da China.

Já Cong et al. (2021) pesquisaram o Mecanismo de Desenvolvimento Limpo (Clean Development Mechanism CDM) de modo a identificarem os determinantes regionais dos projetos de redução de emissões de carbono em 30 províncias chinesas. Os resultados demonstraram que tais projetos são mais propensos de implementação nas regiões com menor PIB per capita, maiores emissões de CO2, maior intensidade energética e quando o montante de empréstimos domésticos em investimentos de ativos fixos é maior.

Em uma abordagem nacional, Azevedo, Oliveira, Buch,
Cavalcante Nascimento e Silva (2017) analisaram se existe relação entre a corrupção, governança e IDH no Brasil. Com base nos resultados, percebeu-se que os estados com maiores índices de corrupção foram os que apresentaram menor IDH e menor nível de governança. Ainda, os autores destacaram que $\mathrm{o}$ aspecto cultural inerente às regiões brasileiras, propicia diferenciações entre as regiões no tocante ao índice de corrupção, indicadores sociais e governança.

\subsubsection{Estrutura de Capital e Regionalidade}

Na literatura, são notórias as evidências de que a estrutura de capital das empresas é determinada por uma combinação de fatores, dentre eles as características das firmas e o ambiente no qual elas estão inseridas (La Rocca et al., 2010; Santos, 2013; Palacín-Sánchez et al., 2013; Palacín-Sánchez \& Di Pietro, 2016; Matias \& Serrasqueiro, 2017; Di Pietro et al., 2018; Ahuja \& Kalra, 2020).

Investigações a este despeito, especialmente em análises de diferentes países (Santos, 2013), são mais recorrentes ao passo que estudos focados nas diferenças institucionais, em um único país e a nível local, incitam investigações (La Rocca et al., 2010). Segundo Di Pietro et al. (2018), os poucos estudos (La Rocca et al., 2010; Palacín-Sánchez et al., 2013; Palacín-Sánchez \& Di Pietro, 2016) cuja análise centra-se nas pequenas e médias empresas de diferentes regiões em um único país, apresentam diferenças nos níveis de endividamento devido ao sistema institucional regional.

Por ambiente institucional, compreende-se os sistemas jurídico, financeiro e tributário, além da cultura nacional (Di Pietro et al., 2018). Nesse aspecto, constata-se a relevância do setor financeiro (Palacín-Sánchez \& Di Pietro, 2016) uma vez que ao escolherem o local para desenvolver as atividades de suas firmas, os empreendedores das pequenas e médias empresas precisam considerar de que modo o aspecto regional afeta a estrutura de capital e o acesso ao financiamento das empresas, uma vez que há certo grau de heterogeneidade regional (Palacín-Sánchez et al., 2013).

Em consonância a esta abordagem, La Rocca et al. (2010) investigaram a influência das diferenças institucionais a nível regional na estrutura de capital e vencimento da dívida de pequenas e médias empresas italianas, dado - desenvolvimento financeiro regional e a eficácia da fiscalização do sistema regional. As principais evidências do estudo destacaram que as decisões corporativas financeiras não são resultado apenas das especificidades das firmas ou da indústria, mas também são baseadas no ambiente institucional em que a empresa opera, visto que a alavancagem da firma se apresentou positivamente 
influenciada pelo desenvolvimento financeiro local.

De maneira complementar, Palacín-Sánchez e Di Pietro (2016) averiguaram o papel do setor financeiro na explicação das diferenças de estrutura de capital de pequenas e médias empresas em diferentes regiões pertencentes à Espanha ao longo dos anos de 1999 a 2007. Foi possível perceber que a estrutura de capital das firmas depende do setor financeiro regional, seja pelo nível de desenvolvimento, bem como pelo grau de competição, que afetam a obtenção de crédito.

Palacín-Sánchez et al. (2013), por sua vez, examinaram se a estrutura de capital de pequenas e médias empresas e os fatores determinantes das firmas diferem-se nas regiões de um determinado país, tendo em vista as empresas das regiões da Espanha no período de 2004 a 2007. Os resultados evidenciaram que tanto a estrutura de capital como o impacto dos fatores determinantes das firmas, que explicam a alavancagem, diferem entre as regiões.

Sob o contexto de Portugal, Matias e Serrasqueiro (2017) dedicaram-se à análise da estrutura de capital de pequenas e médias empresas, localizadas em diferentes regiões de Portugal (NUTS II), durante os anos de 2007 a 2011 . Com base nos resultados, percebeu-se que as características das firmas impactam nas decisões de estrutura de capital, o que corrobora a Teoria Pecking Order, e foram notórias diferenças estatisticamente significantes dos fatores determinantes das firmas e o endividamento das pequenas e médias empresas portuguesas entre as várias regiões.

Já Di Pietro et al. (2018) analisaram como o ambiente institucional regional, sob a ótica do desenvolvimento regional, influencia a estrutura de capital. Os autores destacaram que embora os fatores da empresa e do setor em que atuam expliquem a variação das pequenas e médias empresas, faz-se necessário considerar o ambiente institucional regional para a compreensão do endividamento das pequenas e médias empresas.

\subsection{Pecking Order versus Market Timing}

Um dos trabalhos seminais que incitam a investigação do comportamento de financiamento das empresas é o de Modigliani e Miller (1958). Partindo de pressupostos como do mercado perfeito, estes autores entendem que a origem do financiamento das empresas não afeta o custo de capital nem o valor das empresas. A estrutura de capital é uma das decisões mais importantes da área financeira da empresa e o estudo das teorias que embasam esta vertente tem inspirado muitos autores (Ahuja \& Kalra, 2020). Na literatura atual, não há evidência sólida que consiga evidenciar todas as forças e fraquezas das teorias sobre o financiamento das organizações (Frank \& Goyal, 2009). Em sua maioria, os trabalhos sobre esta abordagem proporcionam evidências empíricas sobre duas teorias contraditórias: Pecking Order e Market Timing (Allini et al., 2018).

A Pecking Order é uma teoria que surge com os trabalhos de Myers (1984) e Myers e Majluf (1984). Segundo estes autores, as organizações possuem ativos que são préestabelecidos, bem como diferentes oportunidades de crescimento. Nesse sentido, as mudanças dos pesos destes dois fatores condicionam a forma como as empresas recorrem às fontes de financiamento. Ademais, o interesse prioritário das organizações no uso dos recursos internos se justifica pela tentativa de diminuição dos custos de emissão, por isso que as empresas mais lucrativas geralmente são menos alavancadas. Dada a necessidade de financiamento externo, a escolha pela dívida se deve ao fato da assimetria informacional. Algumas evidências que corroboram esta abordagem, no que tange aos fatores internos e externo são: Bastos et al. (2009), Frank e Goyal (2009), Kayo e Kimura (2011), Santos (2013), Allini et al. (2017), Bernardo et al. (2018) e Brighetti e Albanez (2019).

Com um posicionamento diferente, os autores Baker e Wurgler (2002) sustentam que as empresas não seguem uma ordem prioritária de obtenção de recursos. Para embasar este posicionamento, eles consideraram a média histórica da variável market-to-book para demonstrar como o "equity markettiming", ou seja, o comportamento do mercado de ações afeta a composição de capital das organizações. Para tanto, em um período de 10 anos, foram consideradas empresas não financeiras, cujos valores contábeis eram superiores a 10 milhões de dólares e cujas datas de IPO (Initial Public Offering) estavam disponíveis. Dentre os principais resultados, eles demonstraram que o Market Timing tem um grande e persistente efeito na estrutura de capital das empresas, sendo as menores alavancagens observadas em momentos de alta valorização do mercado de ações. Portanto, a alavancagem está forte e negativamente relacionada às variações históricas do mercado de ações. Alguns trabalhos que corroboram a evidência destes autores são: Santos (2013); Bernardo et al. (2018) e Kayo e Kimura (2011).

\subsubsection{Estrutura de Capital sob a ótica da Pecking Order}

A respeito da estrutura de capital das empresas, tendo em vista o enfoque na teoria Pecking Order, Bastos et al. (2009) destacaram que os determinantes da estrutura de capital das empresas não são restritos aos fatores das firmas. Eles também analisaram diferentes países (México, Brasil, Argentina, Chile e Peru), sendo consideradas 388 empresas, 
distribuídas em 14 setores, durante o período de 2001 a 2006. Os principais resultados revelaram que o crescimento do PIB apresentou coeficientes negativos e estatisticamente significativos, o que também indica que, em momentos de maior atividade econômica, as empresas tendem a diminuir seus endividamentos.

Em uma abordagem mais ampla, contemplando 40 países durante o período de 1997 a 2007, Kayo e Kimura (2011) analisaram cerca de 17 mil empresas para compreender os determinantes da alavancagem das empresas. De acordo com as evidências, notaram que as características das firmas explicam $42 \%$ da estrutura de capital, enquanto 0 tempo $36 \%$, a indústria $12 \%$, o nível país $3 \%$ e os demais $7 \%$ são explicados pela interação do setor-país. De maneira indireta, as variáveis a nível de indústria e país influenciaram nas decisões de alavancagem, sendo que o PIB demonstrou relação negativa, assim como esperado conforme proposto pela teoria Pecking Order.

Também em uma perspectiva de diferentes cenários econômicos, Santos (2013) investigou a estrutura de capital de 10.423 empresas de 61 países durante o período de 2002 a 2011 . Para este autor, o endividamento está mais relacionado às características das firmas do que às características externas. Entretanto, o ambiente econômico interfere na tomada de decisão de financiamento, sendo, pois, identificada relação negativa do PIB com o endividamento. Isso indica que, em momentos de crescimento econômico, as empresas possuem fluxos de caixa mais elevados e tendem a utilizar mais o débito.

Já os autores Bernardo et al. (2018) consideraram seis países latino-americanos (Argentina, Brasil, Chile, Colômbia, México e Peru), com a intenção de compreender os impactos de fatores macroeconômicos e institucionais na determinação da estrutura de capital das empresas. Foram analisadas 608 empresas não financeiras, cujo patrimônio líquido não foi negativo, e estimadas regressões hierárquicas durante o período de 2009 a 2014. Os principais resultados demonstraram que os fatores macroeconômicos e institucionais são importantes determinantes na estrutura de capital das empresas dos diferentes países. A relação negativa e estatisticamente significativa com o PIB reforçou que, em momentos de crescimento econômico, as empresas são capazes de gerar mais recursos internos e financiar suas atividades, não recorrendo, portanto, ao financiamento externo. Esta evidência corrobora a teoria Pecking Order.

Brighetti e Albanez (2019) sustentam que a estrutura de capital das empresas sofre influência de fatores ambientais, como momentos de ruptura econômica. No caso brasileiro, dois períodos identificados como crise, sendo, pois, os anos de 2008 e 2015, impactaram na limitação da demanda, aumento dos preços e retração do PIB, o que, consequentemente, alterou a disponibilidade de capital disponível para as empresas e refletiu nos custos de captação. Ao analisarem empresas brasileiras, não financeiras, listadas na B3, durante o período de 2008 a 2016, foi possível notar que as empresas tendem a recorrer às dívidas para suprir suas necessidades de capital. No entanto, em momentos de restrições financeiras, as maiores exigências das instituições financeiras podem limitar o acesso ao crédito, levando as organizações a buscarem recursos no mercado de capitais, - que enfraquece a abordagem da Pecking Order (Brighetti \& Albanez, 2019).

Sobre os momentos de recessão econômica, Franzotti e Valle (2020) investigaram o efeito de crises financeiras (2008 e 2015) sobre os investimentos e financiamentos de empresas brasileiras restritas e não restritas durante o período de 2007 a 2016. A amostra de 192 companhias relevou que a crise de 2008 impactou negativa e significativamente a alavancagem de empresas restritas em relação às não restritas. Para estes autores, as crises financeiras, portanto, impactam nas decisões de financiamento e investimento das empresas e os efeitos se diferenciam conforme as características das firmas devido à maior facilidade ou não de obtenção de recursos externos.

Já Cardoso e Pinheiro (2020), com o enfoque no endividamento setorial, contemplaram 211 empresas durante o período de 2010 a 2018, as quais envolveram seis diferentes setores da economia. Eles notaram que PIB foi significante para os setores de materiais básicos e bens industriais. $O$ sinal negativo enfatiza os pressupostos da POT. Ademais, a respeito da recessão, embora não tenha sido possível diferenciar entre os setores cíclico e não cíclicos, os momentos de crise impactaram positivamente no endividamento das empresas, o que sinaliza aumento da alavancagem em função da redução do capital interno.

Vale ressaltar que os autores Bastos et al. (2009) perceberam relação negativa da variável país com as decisões de financiamento, o demonstra que as características únicas dos países os tornam diferentes nas definições das estruturas de capital das empresas. Esta evidência põe em destaque a relevância dos estudos sobre fatores específicos dos países, que no caso da presente pesquisa, corresponde a características específicas das diferentes regiões do Brasil.

Desse modo, considerando as evidências da literatura acerca da relação do PIB com o endividamento das empresas, tem-se a primeira hipótese deste estudo: 
H1: A alavancagem das empresas apresenta relação negativa com o crescimento do PIB municipal.

Ainda sobre a relevância dos fatores externos na determinação das estruturas de capital das empresas, tem-se o enfoque na inflação. A respeito desta abordagem, observam-se estudos que identificaram relação insignificante (Bastos et al., 2009), relação negativa (Cardoso \& Pinheiro, 2020) ou relação positiva (Frank \& Goyal, 2009, Santos, 2013, Bernardo et al., 2018).

Os autores Bastos et al. (2009) entendem que a corrente teórica que explica de forma mais acentuada a estrutura de capital das empresas de diferentes países é a Pecking Order. A respeito da inflação, era esperada uma relação positiva desta variável com o endividamento contábil, visto que a inflação crescente indica depreciação nos montantes nominais das dívidas, sendo mais atraente para as empresas tomarem recursos. No entanto, na amostra considerada, não foi identificada relação estatisticamente significante.

Para Cardoso e Pinheiro (2020), momentos de alta inflacionária geram incerteza para os gestores, o que acarreta maior receio em contrair dívidas de longo prazo. Dessa forma, em relação a esta variável macroeconômica, era esperada relação negativa com o endividamento empresarial, relação esta não comprovada na maioria dos setores, porém que se mostrou estatisticamente significante e negativa para o setor de saúde.

Já Frank e Goyal (2009) destacaram seis fatores essenciais que influenciam na estrutura de capital das empresas, dentre eles a expectativa da inflação. Considerando empresas americanas de 1950 a 2003, eles notaram que os fatores mais notáveis na alavancagem das empresas foram: setor, market-to-book, tangibilidade tamanho e expectativa da inflação. A respeito da inflação, assim como esperado, visualizaram que, quando se espera alta inflação, as empresas tendem a possuir maior alavancagem.

De maneira complementar, Santos (2013) notou relação positiva e estatisticamente significativa entre a inflação anual e a alavancagem das empresas. Isso índica que em ambientes com elevação da taxa de inflação, os agentes tendem a captar recursos em forma de dívida para garantirem maior proteção fiscal.

Por fim, a relação positiva entre a inflação e a alavancagem das empresas, esperada por Bernardo et al. (2018), foi confirmada na realidade dos países latino-americanos. Isto implica dizer que, em altas inflacionárias, há uma retração econômica e maior dificuldade das empresas de gerarem recursos, por isso, espera-se a relação positiva da inflação com a alavancagem das empresas.

Sendo assim, frente a estes apontamentos, visualiza-se a segunda hipótese desta pesquisa:

H2: A alavancagem das empresas apresenta relação positiva com o crescimento da inflação.

Com o enfoque nas características das firmas, ressalta-se o trabalho de Rajan e Zingales (1995). Segundo estes autores, quatro fatores, relacionados às características institucionais são determinantes da estrutura de capital das empresas, a saber: tamanho, ativos tangíveis, lucratividade e valor de mercado sobre o valor contábil. A respeito das duas primeiras características, estes autores afirmam que a relação das variáveis é positiva, enquanto as duas últimas demonstram relação negativa.

Estas mesmas características, segundo Frank e Goyal (2009) são os "core factors" da estrutura de capital. Conforme sustentam estes autores, firmas maiores e com mais ativos tangíveis tendem a ter maior alavancagem. Ademais, as organizações que apresentam maior market-to-book e maiores lucros geralmente possuem menor alavancagem.

Na mesma linha, Kayo e Kimura (2011) notaram que as variáveis-firma tamanho e tangibilidade apresentaram relação positiva com a alavancagem, ao passo que oportunidade de crescimento e lucratividade tiveram comportamento antagônico.

Para Santos (2013), as características das firmas são as mais importantes, sendo que as variáveis oportunidade de crescimento e lucratividade apresentam relação negativa com a alavancagem, enquanto tangibilidade e tamanho relação positiva. A respeito da tangibilidade, entende-se que a oferta de crédito no curto prazo requer garantias para que as empresas tenham acesso aos recursos. Além disso, no tocante ao tamanho das empresas, compreende-se que geralmente as empresas maiores representam menores riscos e, portanto, conseguem captar recursos de uma maneira mais eficiente.

De acordo com Bastos et al. (2009), os determinantes que influenciam de forma mais acentuada a estrutura de capital das empresas são: índice de liquidez corrente, rentabilidade (ROA), market-to-book e tamanho. Diferente dos estudos acima mencionados, estes autores identificaram relação negativa e estatisticamente significativa entre as variáveis market-to-book, rentabilidade (ROA) e liquidez corrente com o financiamento das organizações. 
Para Allini et al. (2017), as variáveis lucratividade, tangibilidade, tamanho e oportunidade de crescimento têm um importante papel para a estrutura de financiamento das organizações, o que reflete a característica de empresas de uma economia emergente. O tamanho da firma, a tangibilidade e o índice market-to-book apresentaram relação positiva, enquanto a lucratividade, relação negativa.

Por fim, Bernardo et al. (2018), ressaltam que as variáveis rentabilidade e liquidez demonstram relação negativa com a alavancagem das empresas, o que indica, respectivamente, que empresas mais rentáveis e com maior folga financeira tendem a utilizar mais recursos internos e são, portanto, menos endividadas.

Dessa forma, são comprovadas diferentes relações empíricas concernentes às características das firmas, o que enfatiza a importância destes fatores na definição da estrutura de capital das empresas. Então, tem-se a terceira hipótese desta pesquisa:

H3: A alavancagem das empresas apresenta relação (positiva/negativa) com as características das firmas.

\subsubsection{Estrutura de Capital sob a ótica da Market Timing}

Com o enfoque na prática de emissão de ações e, de maneira mais específica, contemplando as flutuações temporárias dos custos de emissão em relação aos custos das outras fontes de capital, após a pesquisa de Baker e Wurgler (2002), foi possível notar alguns trabalhos que visaram investigar como a estrutura de capital das empresas sofre influências de questões relacionadas ao tempo do mercado.

O autor Santos (2013) demonstrou que, no contexto do mercado acionário, variáveis como capitalização do mercado e volume negociado de ações apresentaram relação negativa com $\circ$ endividamento das empresas. Isso indica que os países que tinham um mercado acionário mais desenvolvido geralmente possuíam empresas com maior e melhor acesso a formas alternativas de financiamento.

Bernardo et al. (2018), por sua vez, entendem que as empresas tendem a explorar janelas de oportunidade para emissão de títulos, já que foi observada relação negativa entre a variável market-to-book e a alavancagem, destacando que as organizações optam pela emissão de ações em momentos de altos valores de mercado.

Já Kayo e Kimura (2011) notaram que o desenvolvimento do mercado de ações apresentou relação negativa com a alavancagem organizacional, $\circ$ que evidencia que, quando as empresas possuem mais fontes de recursos de financiamento (como a emissão de ações), elas optam por menor endividamento.

Ainda, Muhammad, Yet, Tahir e Nasir (2020) investigaram a realidade de três países emergentes do sul da Ásia (Índia, Paquistão e Bangladesh) durante o período de 2006 a 2017, com o objetivo de explorar o efeito do Market Timing nos mercados de ações e de dívida. Esse estudo abrangeu 2484 observações e as principais evidências apontaram que a estrutura de capital das empresas familiares é impactada pelo Market Timing em ambos os mercados. Isso implica dizer que elas emitem ações quando os preços estão em alta e recompram em baixa. Ademais, estas empresas recorrem ao capital externo ou emitem debêntures quando a taxa de juros está abaixo dos valores históricos.

Diferente das evidências anteriores, Cardoso e Pinheiro (2020), embora também esperassem uma relação negativa da alavancagem com o desempenho do mercado financeiro, encontram uma relação positiva entre $\circ$ endividamento e o valor de mercado dos subsetores. Esta relação positiva e estatisticamente significativa ficou evidente nos setores de bens industriais, materiais básicos, consumo cíclico, consumo não cíclico e saúde. Segundo estes autores, esta evidência contrária à literatura se justifica pela investigação envolver um país emergente, cuja teoria do market timing não se torna apropriada, em consequência de as empresas aumentarem o uso de capital de terceiros frente a períodos que favoreçam a emissão de ações.

Então, em linha com a teoria do Market Timing, visualiza-se a última hipótese deste trabalho:

H4: A alavancagem das empresas apresenta relação negativa com a performance das ações.

\section{Procedimentos Metodológicos}

Neste capítulo, são discutidos os procedimentos metodológicos concernentes a realização do estudo, isto é, são demonstrados os critérios de definição da amostra, as definições das variáveis, bem como a descrição do modelo econométrico.

\subsection{Definições do Estudo}

Para alcance dos objetivos propostos, nesta pesquisa foram consideradas as empresas brasileiras listadas na B3, não financeiras, com valor de mercado superior a R\$10 milhões no ano de 2017. Optou-se por esta seleção, assim como os autores Baker e Wurgler (2002), e Franzotti e Valle (2020). 
Quanto ao período, tendo em vista que este estudo envolve a análise de fatores ambientais e de momentos de ruptura econômica, foi considerado o período de 2007 a 2017, uma vez que abrange dois momentos de recessão econômica, sendo um a nível mundial, subprime americano em 2008, e um nacional, 2015, crise político-econômica. Ressalta-se, ainda, que o estudo não avança além de 2017, pois, em virtude de o enfoque regional envolver o PIB municipal das cidades brasileiras, os dados obtidos no sistema do IBGE (Instituto Brasileiro de Geografia e Estatística) não estão atualizados para períodos mais recentes. Dessa forma, a amostra deste trabalho envolve 426 organizações.

\subsubsection{Variáveis selecionadas na pesquisa}

O Quadro 1 descreve as variáveis do estudo, sendo composto por seis colunas, a saber: (i) variável - nome da variável em análise; (ii) símbolo - sigla que representa a variável nas estimações; (iii) métrica - detalhes sobre a mensuração da variável; (iv) sinal esperado - sinal que se objetiva obter nas estimações; (v) embasamento teórico - estudos que dão sustentação às hipóteses e aos sinais esperados das variáveis e (vi) base de dados - fontes de coletas das informações,

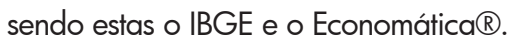

Quadro 1: Descrição das variáveis da pesquisa

\begin{tabular}{|c|c|c|c|c|c|}
\hline Variável & Simbolo & Métrica & $\begin{array}{c}\text { Sinal } \\
\text { Esperado }\end{array}$ & $\begin{array}{c}\text { Emba- } \\
\text { samento } \\
\text { Teórico }\end{array}$ & $\begin{array}{c}\text { Base } \\
\text { de } \\
\text { Dados }\end{array}$ \\
\hline Alavancagem & ALAV & $\begin{array}{c}\text { Dívidas Totais / Ativo } \\
\text { Total }\end{array}$ & & 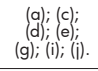 & 2 \\
\hline $\mathrm{PlB}_{M}$ & $\triangle \mathrm{PIB}$ & $\begin{array}{l}\text { Variação anual do PIB } \\
\text { (municipal) }\end{array}$ & $(-)$ & $\begin{array}{l}\text { (c); (d); } \\
\text { (h). }\end{array}$ & 1 \\
\hline Inflaçäo & INF & $\begin{array}{l}\text { Média da taxa anual da } \\
\text { inflaçăo }\end{array}$ & $(+)$ & (c); (d); (i). & 1 \\
\hline Crise & CRISE & $\begin{array}{l}\text { Dummy com valor } 1 \text { para } \\
\text { os anos de } 2008 \text { e } 2015 \\
\text { e } 0 \text { para os demais }\end{array}$ & $(+/-)$ & (g); (i). & 1 \\
\hline $\begin{array}{l}\text { Market Timing-- } \\
\text { Market-to-book }\end{array}$ & MTT (t-1) & $\begin{array}{l}\text { (Valor de Mercado + }+ \\
\text { Valor Total da Divida) / } \\
\text { Afivo Total }\end{array}$ & (-) & $\begin{array}{l}\text { (b); (e); } \\
(\mathrm{i}) ;(\mathrm{k}) \text {. }\end{array}$ & 2 \\
\hline Liquidez Corrente & LIQ & $\begin{array}{l}\text { Ativo Circulante / Passivo } \\
\text { Circulante }\end{array}$ & $(-)$ & $\begin{array}{l}\text { (c); (d); } \\
\text { (e). }\end{array}$ & 2 \\
\hline Rentabilidade* & ROE & $\begin{array}{l}\text { Lucro Líquido / Patrimônio } \\
\text { Liquido }\end{array}$ & (-) & $\begin{array}{l}\text { (a); }(b) ; \\
\text { (cc; }(d) ; \\
\text { (e); }(d) ; \\
\text { (h); (i).; }\end{array}$ & 2 \\
\hline Tangibilidade & TANG & $\begin{array}{c}\text { (Imobilizado + Estoques) / } \\
\text { Ativo Total }\end{array}$ & $(+/-)$ & $\begin{array}{l}\text { (a); (b); } \\
\text { (c); }(d) ; \\
\text { (e); }(d) ; \\
\text { (h); (i).; }\end{array}$ & 2 \\
\hline Tamanho & TAM & Ln (Ativo Total) & $(+/-)$ & $\begin{array}{l}(f) ;(a) ; \\
(g) ;(i) ; .\end{array}$ & 2 \\
\hline Região** & REGIAO & $\begin{array}{l}\text { Variáveis categóricas com } \\
\text { valor } 1 \text { parar a regiáo } \\
\text { Norte, } 2 \text { para Nordeste, } \\
3 \text { Contro-oste, orute } 4 \text { Sudeste } \\
\text { e } 5 \text { Sul }\end{array}$ & & & 1 \\
\hline
\end{tabular}

Embasamento Teórico: (a) Allini et al. (2017); (b) Baker e Wurgler (2002); (c) Bastos et al. (2009); (d) Bernardo et al. (2018); (e) Cardoso e Pinheiro (2020); (f) Frank e Goyal (2009); (g) Franzotti e Valle (2020); (h) Kayo e Kimura (2017); (i) Muhammad et al. (2020); (i) Santos (2013); (k) Setyawan (2011).

Base de Dados: (1) IBGE; (2) Economática ${ }^{\circledR}$

Notas. * Os autores indicados tratam a rentabilidade como ROA, mas nesse estudo será considerado o retorno dos acionistas (ROE); **As regiões foram estabelecidas conforme o endereço da sede da empresa matriz. Fonte: Dados da Pesquisa (2020)

\subsection{Modelo econométrico do estudo}

Esta pesquisa contemplou dados de corte transversal (i) que dizem respeito às empresas listadas na B3 e que fazem parte da amostra, ao longo de uma série temporal (t), cujo período foi de janeiro de 2007 a dezembro de 2017. Por isso, envolve uma dimensão espacial e uma dimensão temporal, sendo, assim, mais indicados os modelos de regressões de dados em painel (Greene, 2002). Neste trabalho, tem-se, portanto, um painel desbalanceado.

Este estudo compreende a análise de dois modelos econométricos, a saber: modelo 1 e modelo 2. O modelo 1 busca estimar as relações do nível de endividamento (ALAV) com as variáveis PIB $(\triangle \mathrm{PIB})$ e inflação (INF) - segundo a Teoria da Pecking Order, conforme equação 1. O modelo 2, por sua vez, investiga a relação do nível de endividamento (ALAV) com o Market Timing (MTT) - equação 2:

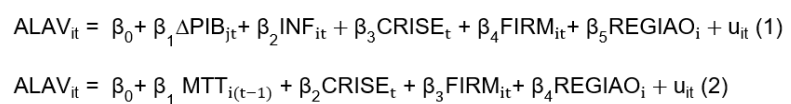

Em que:

$i=$ refere-se à empresa " $i "$

$i=$ refere-se ao PIB do município " $i$ "

$t=$ refere-se ao tempo

FIRM = refere-se às características das firmas, ou seja, às variáveis Liquidez (LIQ), Rentabilidade (ROE), Tangibilidade (TANG) e Tamanho (TAM).

Para estimação dos modelos 1 e 2 deste estudo, conforme equações 1 e 2, procedeu-se, primeiramente, com a análise de normalidade dos dados, por meio da verificação do teste de Kolmogorov-Smirnov. Ademais, realizou-se o teste de Variance Inflation Factor (VIF), cuja média foi correspondente a 1,19 para o modelo 1 e 1,02 para o modelo 2, o que indica não haver multicolinearidade entre as variáveis do modelo. Os testes Wooldridge e Wald mostraram que há presença de autocorrelação e heterocedasticidade e ambos foram tratados utilizando o erro padrão robusto de White. As regressões foram estimadas por mínimos quadrados ordinários (MQO), com dados empilhados.

\section{Resultados e discussões}

Esta seção traz a estatística descritiva dos dados, bem como a discussão dos modelos econométricos conforme as teorias Pecking Order e Market Timing, as quais sustentam as quatro hipóteses deste estudo. 


\subsection{Análise Descritiva}

Na tabela 1, é possível identificar que as cinco regiões não estão proporcionalmente representadas, em virtude de a amostra envolver 426 empresas com valor de mercado superior a R\$10 milhões, as quais concentram-se nas regiões Sul e Sudeste. Nestas duas regiões, situam-se as sedes de mais de $86 \%$ das empresas, sendo São Paulo (45\%) o estado mais expressivo.

Tabela 1: Análise de Frequência da Região

\begin{tabular}{|c|c|c|c|c|}
\hline Região & N. & $\%$ & Empresas & $\%$ \\
\hline Norte & 44 & 0,94 & 4 & 0,94 \\
\hline Nordeste & 407 & 8,69 & 37 & 8,69 \\
\hline Centro-Oeste & 154 & 3,29 & 14 & 3,29 \\
\hline Sudeste & 3.344 & 71,36 & 304 & 71,36 \\
\hline Sul & 737 & 15,73 & 67 & 15,73 \\
\hline Total & 4686 & 100 & 426 & 100 \\
\hline
\end{tabular}

Fonte: Resultados da Pesquisa (2020)

A estatística descritiva das variáveis dependentes e independentes do estudo está expressa na tabela 2. Nesta tabela, é possível notar que as empresas investigadas possuem dívidas (ALAV) correspondentes a, aproximadamente, 54\% do ativo total, sendo a região Norte em destaque com o maior indicador de alavancagem (87\%) e a Nordeste com o menor (26\%). Ademais, as organizações possuem boa capacidade de pagamento (LIQ), já que o ativo circulante é cerca de 7 vezes maior que as obrigações de curto prazo, sendo, pois, os ativos tangíveis (TANG) correspondentes a, aproximadamente, $34 \%$ do ativo total. A região, cujas empresas possuem maior variabilidade do indicador de liquidez é a região Sudeste $(112,68)$, por ser esta a região que contempla $71 \%$ das companhias do estudo.

Sobre o comportamento das empresas no mercado (MTT), o valor de mercado associado ao total das dívidas é superior ao ativo total (142\%). A respeito deste indicador, a região Sudeste sobressai com $156 \%$ e a Centro-Oeste com o menor valor $69 \%$. Em relação à rentabilidade (ROE), em média, foi observado que as organizações garantem um retorno aos acionistas de 7,36\%, apesar de nas regiões Norte e CentroOeste, em média, as empresas apurarem prejuízo contábil, com ROE negativos de, respectivamente, - $-19,27 \%$ e $-55,35 \%$. No entanto, a maior rentabilidade média auferida aos acionistas é observada na região Nordeste (26,57\%).

Por fim, o tamanho médio (TAM) das empresas é de $R \$$ 1,71 bilhões $\left(e^{14,35}\right)$, sendo o destaque para região CentroOeste, cujas empresas possuem uma média de ativo total correspondente a $R \$ 4,64$ bilhões $\left(e^{15,35}\right)$ e para região Sul, com organizações de tamanho equivalente a $R$ \$ 0,89 bilhões $\left(e^{13,70}\right)$.

Tabela 2: Estatística Descritiva das Variáveis

\begin{tabular}{|c|c|c|c|c|c|c|c|c|}
\hline Região & Medida & ALAV & MTT & APIB & UQ & ROE & TAM & TANG \\
\hline Norte & Média & 0,8725 & 1,4730 & $9,73 \%$ & 0,6300 & $-19,27 \%$ & 14,2956 & 0,4271 \\
\hline & DP & 1,1984 & 1,3517 & $11,45 \%$ & 0,4735 & $115,86 \%$ & 1,1970 & 0,3954 \\
\hline Nordeste & Média & 0,2581 & 1,0545 & $9,64 \%$ & 2,3914 & $26,57 \%$ & 14,1074 & 0,4071 \\
\hline & DP & 0,1903 & 0,6525 & $7,42 \%$ & 3,7213 & $244,33 \%$ & 2,0093 & 0,3062 \\
\hline $\begin{array}{c}\text { Centro- } \\
\text { Oeste }\end{array}$ & Média & 0,3627 & 0,6949 & $11,48 \%$ & 1,3437 & $-55,35 \%$ & 15,3513 & 0,2643 \\
\hline & DP & 0,4245 & 0,9281 & $6,75 \%$ & 1,4540 & $604,20 \%$ & 1,4608 & 0,2791 \\
\hline Sudeste & Média & 0,6223 & 1,5684 & $9,10 \%$ & 9,6405 & $7,87 \%$ & 14,5039 & 0,3105 \\
\hline & DP & 5,9342 & 7,6433 & $8,57 \%$ & 112,6813 & $329,92 \%$ & 2,1235 & 0,2759 \\
\hline Sul & Média & 0,3424 & 1,0738 & $9,82 \%$ & 1,4986 & $6,54 \%$ & 13,6981 & 0,4425 \\
\hline & DP & 0,3629 & 0,9095 & $8,93 \%$ & 1,7250 & $180,82 \%$ & 1,8037 & 0,2483 \\
\hline Total & Média & 0,5370 & 1,4171 & $9,34 \%$ & 7,2972 & $7,36 \%$ & 14,3559 & 0,3410 \\
\hline & DP & 4,9851 & 6,4384 & $8,52 \%$ & 94,5809 & $313,15 \%$ & 2,0688 & 0,2812 \\
\hline
\end{tabular}

Fonte: Resultados da Pesquisa (2020)

Como já destacado, para este estudo, a regionalidade foi expressa de duas formas, a saber: (i) pela variável PIB, cujos valores são a nível municipal; e (ii) pelo endereço da sede da empresa matriz. Assim como retratado na literatura, entendese que o ambiente, no qual as empresas estão inseridas, interfere nas decisões de financiamento das organizações, sendo, pois, esta influência percebida com enfoque em pequenas e médias empresas. Desse modo, ao extrapolar para a perspectiva das grandes empresas, como no caso deste estudo, apesar de não haver regiões equitativamente representadas, na tabela 3, destacam-se as variações do PIB municipal, conforme as unidades federativas e pelas cinco regiões contempladas:

Tabela 3: Indicador Regional - $\triangle$ PIB municipal

\begin{tabular}{|c|c|c|c|c|}
\hline Região & UF & N & Média & DP \\
\hline \multirow{7}{*}{ Norte } & AM & 11 & $7,73 \%$ & $6,00 \%$ \\
\cline { 2 - 5 } & PA & 11 & $8,04 \%$ & $6,47 \%$ \\
\cline { 2 - 5 } & TO & 22 & $11,57 \%$ & $14,98 \%$ \\
\cline { 2 - 5 } & Total & 44 & $9,73 \%$ & $11,45 \%$ \\
\hline \multirow{7}{*}{ Nordeste } & BA & 121 & $8,16 \%$ & $9,20 \%$ \\
\cline { 2 - 5 } & CE & 132 & $10,40 \%$ & $5,34 \%$ \\
\cline { 2 - 5 } & MA & 33 & $9,35 \%$ & $8,55 \%$ \\
\cline { 2 - 5 } & PB & 22 & $10,51 \%$ & $6,95 \%$ \\
\cline { 2 - 5 } & PE & 55 & $9,74 \%$ & $7,21 \%$ \\
\cline { 2 - 5 } & RN & 33 & $11,40 \%$ & $6,54 \%$ \\
\cline { 2 - 5 } & SE & 11 & $10,08 \%$ & $7,04 \%$ \\
\cline { 2 - 5 } & Total & 407 & $9,64 \%$ & $7,42 \%$ \\
\hline \multirow{7}{*}{ Centro-Oeste } & DF & 33 & $10,20 \%$ & $4,13 \%$ \\
\hline & GO & 33 & $9,56 \%$ & $5,48 \%$ \\
\cline { 2 - 5 } & MS & 44 & $12,51 \%$ & $7,67 \%$ \\
\hline & MT & 44 & $12,86 \%$ & $7,82 \%$ \\
\cline { 2 - 5 } & Total & 154 & $11,48 \%$ & $6,75 \%$ \\
\hline
\end{tabular}




\begin{tabular}{|c|c|c|c|c|}
\hline \multirow{3}{*}{ Sudeste } & ES & 44 & $6,90 \%$ & $10,57 \%$ \\
\cline { 2 - 5 } & MG & 396 & $10,02 \%$ & $11,43 \%$ \\
\cline { 2 - 5 } & RJ & 792 & $9,33 \%$ & $5,58 \%$ \\
\cline { 2 - 5 } & SP & 2112 & $8,88 \%$ & $8,81 \%$ \\
\cline { 2 - 5 } & Total & 3344 & $9,10 \%$ & $8,57 \%$ \\
\hline \multirow{3}{*}{ Sul } & PR & 198 & $10,11 \%$ & $9,77 \%$ \\
\cline { 2 - 5 } & RS & 286 & $9,68 \%$ & $9,65 \%$ \\
\cline { 2 - 5 } & SC & 253 & $9,74 \%$ & $7,27 \%$ \\
\hline \multicolumn{2}{|c|}{ Total } & 737 & $9,34 \%$ & $8,93 \%$ \\
\hline
\end{tabular}

Fonte: Resultados da Pesquisa (2020)

Assim como demonstrado nas tabelas 2 e 3 , a variação média do PIB foi de $9,34 \%$ ao longo dos 10 anos de análise. Por um lado, a região com maior variação média deste indicador foi a Centro-Oeste, com destaque para o estado do Mato Grosso (12,86\%). Por outro lado, a região Sudeste teve a menor variação $(9,10 \%)$, com ênfase para o Espírito Santo $(6,90 \%)$.

\subsection{Análise e Discussão dos Resultados das Regressões}

Para responder aos objetivos propostos, foram estabelecidas quatro hipóteses, segundo as quais a alavancagem das empresas é justificada pela Teoria Pecking Order e/ou pela Teoria Market Timing. Conforme a abordagem POT, a alavancagem das empresas pode ter influência de fatores externos (como as variáveis macroeconômicas) e de fatores internos (características das firmas). Já a abordagem MTT sustenta que as decisões de financiamento são afetadas pelo comportamento passado do mercado de ações.

Frente a isto, dois modelos econométricos foram estimados, sendo que o modelo 1 envolveu as variáveis macroeconômicas PIB e inflação, enquanto o modelo 2, a variável MTT. Os dois modelos envolveram as demais variáveis que expressam as características das firmas. Foram realizados os testes de Breusch-Pagan, bem como Hausman para verificar qual seria a melhor forma de estimação e, embora tenha sido indicado que o modelo 1 fosse estimado com efeitos aleatórios e 0 modelo 2 com dados empilhados, optou-se por estimar os dois modelos com dados empilhados de forma a identificar as relações propostas, tendo, pois o controle por região, setor e ano. Dessa forma, os modelos econométricos foram estimados por regressões lineares múltiplas com dados empilhados (POLS) e com erros-padrão robustos (tabela 4).
Tabela 4: Análise da Alavancagem conforme a Teoria Pecking Order e a Teoria do Market Timing

\begin{tabular}{|c|c|c|c|c|c|c|}
\hline \multirow{2}{*}{ Variáveis } & \multicolumn{3}{|c|}{ Modelo 1} & \multicolumn{3}{|c|}{ Modelo 2} \\
\hline & Beta & P-valor & Sig & Beta & P-valor & Sig \\
\hline PIB & 2,0980 & 0,2360 & & & & \\
\hline INF & $.0,3309$ & 0,0960 & $*$ & & & \\
\hline MTT & & & & 0,5767 & 0,1690 & \\
\hline CRISE & 2,5121 & 0,0910 & * & 0,4386 & 0,3070 & \\
\hline LIQ & $-0,0005$ & 0,0420 & ${ }^{* *}$ & $-0,0257$ & 0,1070 & \\
\hline ROE & $-0,0010$ & 0,8280 & & 0,0010 & 0,8950 & \\
\hline TANG & 1,1026 & 0,0000 & *** & 0,6591 & 0,0240 & ** \\
\hline TAM & $-0,2140$ & 0,0280 & ${ }^{* *}$ & $-0,2122$ & 0,0580 & * \\
\hline \multicolumn{7}{|l|}{ REGIÃO } \\
\hline Norte & . & & & . & & \\
\hline Nordeste & $-0,4744$ & 0,0130 & ** & $-0,6783$ & 0,0080 & $* * *$ \\
\hline Centro-Oeste & $-0,0802$ & 0,7290 & & $-0,4586$ & 0,2090 & \\
\hline Sudeste & $-0,0415$ & 0,8620 & & $-0,4630$ & 0,0740 & * \\
\hline Sul & $-1,0010$ & 0,0010 & ${ }^{* * *}$ & $-1,0686$ & 0,0010 & *** \\
\hline _const & 4,1682 & 0,0080 & *** & 2,9726 & 0,1350 & \\
\hline Setor & \multicolumn{3}{|c|}{ Sim } & \multicolumn{3}{|c|}{ Sim } \\
\hline Ano & \multicolumn{3}{|c|}{ Sim } & \multicolumn{3}{|c|}{ Sim } \\
\hline N & \multicolumn{3}{|c|}{3984} & \multicolumn{3}{|c|}{2414} \\
\hline VIF & \multicolumn{3}{|c|}{1,19} & \multicolumn{3}{|c|}{1,02} \\
\hline Wooldrigde & \multicolumn{3}{|c|}{0,0000} & \multicolumn{3}{|c|}{0,0000} \\
\hline Wald & \multicolumn{3}{|c|}{0,0000} & \multicolumn{3}{|c|}{0,0000} \\
\hline
\end{tabular}

Nota. Resultados dos modelos de regressão linear múltipla (Equação $1 \mathrm{e}$ Equação 2). Os asteriscos indicam os níveis de significância: * $p<0,10$; ${ }^{* *} p<0,05 ;{ }^{* * *} p<0,01$. Os modelos foram estimados com dummies para região e com erros robustos. Quanto a variável dependente, adotou-se, em todos os modelos, a variável "ALAV" (alavancagem), sendo que, no modelo 1, foram consideradas as variáveis independentes "PIB" (variação do PIB) e "INF" (inflação) e, no modelo 2, a variável "MTT" (market timing). Os dois modelos foram estimados, considerando as mesmas variáveis que expressam as características das firmas e as variáveis de controle.

Fonte: Resultados da pesquisa (2020)

Assim, como se observa na tabela 4, nos dois modelos nem todas as variáveis apresentam relação estatisticamente significante com a alavancagem pelo menos ao nível de $10 \%$. Conforme abordagem da Pecking Order, no modelo 1, ao considerar as variáveis macroeconômicas PIB $(\triangle \mathrm{PIB})$ e inflação (INF), o nível de endividamento das empresas (ALAV) não apresenta relação estatisticamente significante com o PIB, mas apresenta relação negativa e significante a 10\% com a inflação. Estas evidências não respondem, portanto, às primeiras duas hipóteses do estudo. 
Em relação ao PIB $(\triangle P I B)$, embora alguns autores, como Bastos et al. (2009), Kayo e Kimura (2011) e Bernardo et al. (2018) e Cardoso e Pinheiro (2020), sugerem relação negativa entre a variação do PIB e a alavancagem das empresas (ALAV), não foi possível rejeitar a hipótese nula de ausência de significância entre estas variáveis. Isso indica que apesar dos momentos de recessão ou crescimento econômico influenciarem na lucratividade das empresas, não é possível inferir que a variação do PIB é um fator predominante na definição da estrutura de capital das empresas e, portanto, não se confirmou a hipótese HI desse estudo. Segundo Palacín-Sánchez et al. (2013), o PIB per capita é um indicador clássico da diferença de riquezas entre as regiões $\mathrm{e}$, nesse sentido, a taxa média de crescimento anual do PIB pode ser compreendida como indicador da necessidade de financiamento das empresas, o que justifica $\circ$ porquê de algumas regiões e, consequentemente, suas empresas, crescerem mais rapidamente do que outras.

No que se refere à inflação (INF), a evidência negativa e estatisticamente significante ao nível de $10 \%$ é contrária ao que os autores Bastos et al. (2009), Santos (2013) e Bernardo et al. (2018) indicam. Esperava-se, portanto, conforme hipótese $\mathrm{H} 2$, que, em situações de alta inflacionária, em virtude da retração econômica e, consequente, maior dificuldade das empresas de gerarem recursos, haveria maior uso de recursos de terceiros. Não obstante, esta evidência negativa corrobora o trabalho de Cardoso e Pinheiro (2020), o que sinaliza que as empresas, cujos setores possuem baixa elasticidade da demanda, se beneficiam com a alta dos preços.

Ressalta-se que, apesar da Pecking Ordernão ser corroborada pela análise das variáveis do ambiente externo (PIB e inflação), foi observada relação positiva e estatisticamente significante, ao nível de $10 \%$, com a variável crise. Isso indica que, em situações de retração da economia, sendo neste estudo representadas pelos anos 2008 e 2015, é possível inferir que há maior endividamento das empresas. Assim como argumentam Franzotti e Valle (2020), as crises financeiras podem gerar impactos significativos tanto nas decisões de financiamento quanto de investimento das empresas, pois afetam a obtenção dos recursos externos. Cabe destacar que a relação positiva e estatisticamente significativa observada se justifica, pois, em momento de instabilidade econômica, as organizações podem ter perda na capacidade de produção de riqueza (Santos, 2013), o que as faz recorrer ao capital de terceiros (Cardoso \& Pinheiro, 2020).

Ainda, sobre o modelo 1, e tendo em vista a hipótese H3 deste estudo que versa sobre a características das firmas, foi possivel observar relação negativa e estatisticamente significante ao nível de $5 \%$ entre a alavancagem (ALAV) e as variáveis liquidez (LIQ) e tamanho das empresas (TAM). Ademais, notou-se relação positiva e estatisticamente significante ao nível de $1 \%$ com a variável tangibilidade (TANG). No entanto, não foi observada nenhuma relação estatisticamente significante com a rentabilidade (ROE). Estas evidências respondem à hipótese $\mathrm{H} 3$ e indicam que o financiamento das organizações é determinado por fatores internos.

Em relação à liquidez $(L I Q)$, a relação negativa corrobora a Pecking Order e os estudos de Bastos et al. (2009) e Bernardo et al. (2018). Desse modo, entende-se que, quando as empresas apresentam mais recursos disponíveis no curto prazo, ou seja, quando as empresas são mais solventes, elas tendem a se endividar menos, por optarem pelo uso dos recursos internos.

A respeito da variável tamanho (TAM), a relação negativa indica que as empresas maiores estão mais propensas a serem mais diversificadas o que, consequentemente, as possibilita melhores condições para emitir ações ao invés de recorrer à emissão/contratação de dívida (Franzotti \& Valle, 2020).

Já a variável tangibilidade (TANG), ao apresentar-se positiva e estatisticamente relacionada à alavancagem, corrobora a Pecking Order, já que empresas mais tangíveis estão mais suscetíveis à assimetria de informações e, então, optam pelo financiamento externo antes da emissão de ações (Allini et al., 2017).

Cumpre destacar que a relação negativa observada com a variável região (REGIÃO), que indica a localização da empresa matriz, impacta na decisão de financiamento das organizações. Os trabalhos que embasam este estudo não apresentam uma análise regional, mas alguns (Bastos et al., 2009; Santos, 2013; Bernardo; Albanez \& Securato, 2018) destacam que o controle realizado por país foi significativo.

A respeito da abordagem Market Timing, expressa no modelo 2 , era esperada a relação negativa entre a alavancagem (ALAV) e a variável MTT, conforme a hipótese $\mathrm{H} 4$ deste trabalho. No entanto, não houve evidências suficientes para rejeitar a hipótese nula de ausência de significância. Sendo assim, não foi possível corroborar a influência do mercado de capitais nas decisões de financiamento das empresas, seja esta negativa conforme os estudos de Baker e Wurgler (2002), Setyawan (2011) e Muhammad et al (2020) ou mesmo positiva de acordo com Cardoso e Pinheiro (2020). Nesse sentido, por se tratar de um país emergente, a teoria Market Timing não é uma abordagem relevante para justificar o nível de endividamento das organizações (Cardoso \& 
Pinheiro, 2020). Isto indica que, para a amostra em estudo, não é possível inferir que as decisões de financiamento das empresas estejam relacionadas ao momento do mercado de capitais, ou seja, ao bom desempenho passado.

No modelo 2, a respeito das características das empresas, as evidências encontradas são correspondentes às já destacadas no modelo $\mathrm{l}$, as quais sustentam a abordagem Pecking Order.

\section{Considerações Finais}

Este estudo visou compreender como os fatores macroeconômicos e as características das firmas impactam na definição da estrutura de capital das empresas brasileiras, tendo em vista o contexto regional. Desse modo, a investigação foi fundamentada conforme a Teoria Pecking Order e a Teoria Market Timing. Para tanto, foram consideradas 426 empresas brasileiras não-financeiras, listadas na B3, durante o período de 2007 a 2017. Os modelos econométricos foram estimados com dados empilhados e correção com erros robustos.

Dentre as quatro hipóteses propostas, foi corroborada somente a hipótese $\mathrm{H} 3$, a qual discorre sobre os impactos das características das firmas, podendo estes ser negativos ou positivos conforme evidências da literatura. Nesse sentido, foi observada relação negativa da alavancagem financeira com a liquidez das empresas, o que assevera que as organizações, quando possuem mais recursos disponíveis no curto prazo, isto é, quando estão mais solventes, tendem a reduzir a captação de recursos de terceiros.

Além disso, notou-se relação positiva com a variável tangibilidade e negativa com o tamanho. Em relação à tangibilidade, entende-se que as empresas mais tangíveis são mais passíveis de assimetria informacional, por isso, geralmente optam pelo financiamento externo anteriormente à emissão de ações. No que diz respeito ao tamanho, empresas maiores tendem a ser mais diversificadas $e$, consequentemente, possuem condições mais favoráveis para a emissão de ações.

Destarte, ao corroborar a hipótese $\mathrm{H} 3$, entende-se que as evidências reforçam a teoria Pecking Order, visto que as organizações, em virtude de suas características, anseiam, prioritariamente, pela utilização dos recursos internos, depois pela emissão/captação de dívida e, por fim, pela emissão de ações.

Não obstante à ausência de evidências suficientes para ratificar as hipóteses $\mathrm{H} 1$ e H2, entende-se que, em momentos de instabilidade econômica, como durante as crises de
2008 e 2015, as empresas estão mais suscetíveis à redução dos lucros, o que as direciona à obtenção de recursos de terceiros, por isso a relação positiva entre a alavancagem e a crise foi observada. Esta constatação, similarmente, é sustentada pela teoria Pecking Order.

Sobre a teoria Market Timing, não houve evidências suficientes para rejeitar a hipótese nula de ausência de significância correspondente à $\mathrm{H} 4$, assim dizendo, não foi observada a relação negativa, que era esperada entre as variáveis alavancagem e market-to-book. Isto denota que o financiamento das empresas geralmente não é condicionado pelo desempenho passado no mercado de ações.

Cabe salientar a importância da investigação em um contexto regional, já que a relação negativa com as regiões adotadas demonstra, estatisticamente, influência da localização das empresas matrizes, sendo que a maioria das empresas pertence às regiões sudeste e sul (86\%). Ademais, a ausência de relação entre as decisões de financiamento das organizações (ALAV) e a variação do PIB municipal ( $\triangle P I B)$, diferente da literatura, justifica-se pelo perfil da amostra investigada, já que a abordagem regional é contemplada, sobretudo, em análises de pequenas e médias empresas.

Frente a estes indícios, entende-se que este estudo apresenta importantes contribuições para os agentes econômicos, não só pelo enfoque no mercado, voltado para reguladores e investidores, mas também para os gestores terem a real compreensão das estruturas de capital das empresas e, consequentes, custos das dívidas. Ademais, na perspectiva teórica, oportuniza mais evidências empíricas que vão ao encontro da teoria Pecking Order.

Este estudo demonstra limitações referentes ao período da análise, pois, alguns dados, como o PIB por município só estavam disponíveis até o ano de 2017, o que inviabilizou a investigação dos anos mais atuais. Além disso, para expressar a realidade macroeconômica, foram utilizadas somente as variáveis PIB e inflação, tendo, de maneira complementar, a identificação dos períodos de crise, como os anos 2008 e 2015. Destaca-se, também, o recorte amostral que contemplou apenas empresas brasileiras listadas na B3, não financeiras, com valor de mercado superior a $R \$ 10$ milhões no ano de 2017, o que pode ter influenciado na concentração de empresas nas regiões Sudeste e Sul e, por consequência, na pouca sensibilidade do aspecto regional nos resultados observados.

Por conseguinte, sugere-se que estudos futuros apresentem novas variáveis macroeconômicas, como o índice de Gini, bem como uma análise em séries mais fracionados, como 
análise trimestral, de modo a captar maior variabilidade, além de uma abordagem sobre a regionalidade que inclua outros indicadores, conforme os estudos de La Rocca et al. (2010), Palacín-Sánchez et al. (2013), Palacín-Sánchez \& Di Pietro (2016), Matias \& Serrasqueiro (2017) e Di Pietro et al. (2018)

\section{Referências}

Ahuja, B. R., \& Kalra, R. (2020). Impact of macroeconomic variables on corporate capital structure: a case of India. Managerial Finance. Vol. ahead-of-print No. ahead-ofprint.

Allini, A., Rakha, S., McMillan, D. G., \& Caldarelli, A. (2018). Pecking Order and Market Timing Theory in Emerging markets: The case of Egyptian firms. Research in International Business and Finance, 44(1), 297-308. Doi: 10.1016/i.ribaf.2017.07.098

Azevedo, E. B., Oliveira, A. G., Buch, C. L., Cavalcante Nascimento, T. \& Silva, C. L. (2018). Corrupção, governança e desenvolvimento: uma análise seccional de dados para o Brasil. GCG Georgetown University Universia, 12(1), 48-62. Doi: 10.3232/GCG.2018.V12. N1.02

Baker, M., \& Wurgler, J. (2002). Market Timing and Capital Structure. The Journal of Finance, LVII (1). Doi: $10.1111 / 1540-6261.00414$

Bastos, D. D., Nakamura, W. T., \& Basso, L. F. C. (2009). Determinantes da Estrutura de Capital das Companhias Abertas na América Latina: Um Estudo Empírico Considerando Fatores Macroeconômicos e Institucionais. Revista de Administração Mackenzie (RAM), 10(6), 47-77. Doi: 10.1590/S1678-69712009000600005

Bernardo, C. J., Albanez, T., \& Securato, J. R. (2018). Fatores Macroeconômicos e Institucionais, Composição do Endividamento e Estrutura de Capital de Empresas Latino-Americanas. Brazilian Business Review, 15(2), 152 174. Doi: 10.15728/bbr.2018.15.2.4

Brighetti, E., \& Albanez, T. (2019). Decisões de Financiamento de Empresas Brasileiras em Cenários de Crise sob a Perspectiva da Teoria de Pecking Order. In. XVI CONGRESSO USP DE INICIAÇÃO CIENTÍFICA EM CONTABILIDADE, 2019, USP. Anais [....] São Paulo: Universidade de São Paulo.

Cardoso, V. R. S., \& Pinheiro, M. C. (2020) Influência da recessão e das variáveis macroeconômicas sobre a estrutura de capital setorial. Revista Contabilidade \& Finanças, 31(84), 392-408. Doi: 10.1590/1808057x201908100

Cong, R., Lo, A. Y., \& Yu, W. (2021). The distribution and regional determinants of nationally financed emissionsreduction projects in China. Energy Policy, 152, 112215. Doi: 10.1016/j.enpol.2021.112215

Di Pietro, F., Palacín Sánchez, M. J., \& Roldán Salgueiro, J. L. (2018). Regional development and capital structure of SMEs. Cuadernos de Gestión, 18 (1), 37-60. Doi: https:// doi.org/10.5295/cdg.150530fd

Frank, M. Z., \& Goyal, V. (2009). Capital Structure Decisions: Which Factors Are Reliably Important? Financial Management., 38(1), 1-37. https://www.jstor. org/stable/20486683

Franzotti, T. D. A., Valle, M. R. (2020). Impacto de crises sobre investimentos e financiamentos de companhias brasileiras: abordagem no contexto de restrições financeiras. Brazilian Business Review, 17(2), 233-252. Doi: 10.15728/bbr.2020.17.2.6

Gil, A. C., Oliva, E. C., Novais, M. B. C., \& Silva, E. C. (2013). Fundamentos Científicos da Gestão para $\bigcirc$ Desenvolvimento da Regionalidade. Revista de Ciências da Administração, 15(35), 68-81. Doi: $10.5007 / 2175-8077.2013 v 15 n 35 p 68$

Greene, W.H. (2002). Econometric Analysis. 5th Edition, Prentice Hall, Upper Saddle River, 802.

Hasan, I., Kobeissi, N., Wang, H., \& Zhou, M. (2017). Bank financing, institutions and regional entrepreneurial activities: Evidence from China. International Review of Economics \& Finance, 52, 257-267. Doi: 10.1016/i. iref.2017.01.013

Jahanzeb, A. (2013). Trade-Off Theory, Pecking Order Theory and Market Timing Theory: A Comprehensive Review of Capital Structure Theories. Economics Bulletin, $33(1), 1-6$.

Kayo, E. K., \& Kimura, H. (2011). Hierarchical determinants of capital structure. Journal of Banking \& Finance, 35(2), 358-371. Doi: 10.1016/i.jbankfin.2010.08.015

La Rocca, M., La Rocca, T., \& Cariola, A. (2010). The influence of local institutional differences on the capital 
structure of SMEs: Evidence from Italy. International 13(2), 187-222. Doi: 10.1016/0304-405X(84)90023-0 Small Business Journal, 28(3), 234-257. Doi: $10.1177 / 0266242609360614$

Palacín-Sánchez, M.J., Ramírez-Herrera, L., \& Di Pietro, F. (2013). Capital structure of SMEs in Spanish regions. Small Lv, C., Bian, B., Lee, C. C., \& He, Z. (2021). Regional Business Economics, 41 (2), 403-519. Doi: 10.1007/ gap and the trend of green finance development in s11187-012-9439-7

China. Energy Economics, 102, 105476. Doi: 10.1016/i. eneco.2021.105476

Palacín-Sánchez, M.J, \& Di Pietro, F. (2016). The role of the regional financial sector in the capital structure of small

Matias, F., \& Serrasqueiro, Z. (2017). Are there reliable determinant factors of capital structure decisions? Empirical study of SMEs in different regions of Portugal. Research in International Business and Finance, 40, 19-33. Doi: 10.1016/j.ribaf.2016.09.014

Modigliani, F., \& Miller, M. H. (1958). The cost of capital, corporation finance and the theory of investment. The American Economic Review, 48(3), 261-297. http://www. jstor.org/stable/1812919.

Muhammad, M., Yet, C. E., Tahir, M., Nasir, A. M. (2020). Capital structure of family firms: the effect of debt and equity market timing. Journal of Family Business Management, Vol. ahead-of-print No. ahead-of-print, 2020. Doi: 10.1108/JFBM-09-2019-0059 and medium-sized enterprises (SMEs). Regional Studies. 70 (7), 1232-1247. Doi: 10.1080/00343404.2014.1000290

Pettinati, A. (2012). Regionalidade e OrganizaçõesPrograma de Pós Graduação em Administração da Universidade de São Caetano do Sul, Páginas \& Letras, 2012. 250p. Gestão \& Regionalidade, 28(83), 129-130.

Rajan, R. \& Zingales, L. (1995). What do we know about capital structure? Some evidence from international data. The Journal of Finance, 50(5), 1421-1460. Doi: https://doi. org/10.1111/j.1540-6261.1995.tb05184.x

Santos, M. A. (2013). Determinantes da estrutura de capital de empresas em diferentes cenários econômicos e institucionais: um estudo comparativo. Dissertação de Mestrado - Departamento de Contabilidade, Faculdade Myers, S. C. (1984). Capital structure puzzle. The Journal of de Economia, Administração e Contabilidade de Ribeirão Finance, 39(3), 575-592. Doi: 10.1111/j.1540-6261.1984. Preto, Universidade de São Paulo, Ribeirão Preto. tb03646.x

Setyawan, I. R. (2011). An Empirical Study on Market Myers, S., Majluf, N. (1984). Corporate financing and Timing Theory of Capital Structure. International Research investment decisions when firms have information that Journal of Business Studies, 4(2), 103-199. Doi: 10.21632/ investors do not have. Journal of Financial Economics, iribs.4.2.103-119 